\title{
Scene Design of Huawei's Advertising on Movie and TV from a Post-colonial Perspective
}

\author{
Yaling Zhang ${ }^{1, *}$
}

\author{
${ }^{1}$ Wuhan Textile University, Wuhan, Hubei, China \\ *Corresponding author. Email: 931101256@qq.com
}

\begin{abstract}
This article starts with the scene design in Huawei's advertising on movie and TV and discusses the transformed as well as the untransformed Chinese scenes in the narrative of China's progress in Huawei advertising from the perspective of post-colonial related theories, explaining the reasons for "being transformed" and "being untransformed". Huawei is trying to break the contradictory state of this imagination while catering to the Western imagination. It is the wise choice for Huawei advertising in the scene design to show the real Chinese scene.
\end{abstract}

Keywords: Post-colony, Huawei's advertising on movie and TV, Scene design.

\section{INTRODUCTION}

Western society is progressing rapidly. Westerners see China stagnating in their own progress, and establish a stagnant and civilized Chinese image while establishing a progressive historical concept. ${ }^{1}$ Circumstances change with the passage of time, and whether modern China is stagnant or not is not important to the West. What is important is that the stagnant image of China is a tool used to establish the advanced nature of the West. Orientalist Said believes that "modern East has participated in its own orientalization", namely, the East has accepted the stagnant image of China created by the West, catered to the "East in the eyes of Westerners", and fell into the predicament of not being able to find its own identity positioning. This dilemma is clearly reflected in Huawei's advertising on movie and TV. Huawei hopes to build a modern image, but modernization itself is accompanied by Westernization.

\section{THE CHINESE SCENE TO BE REFORMED IN THE NARRATIVE OF CHINESE PROGRESS}

Reform and opening up has brought China's rapid economic development, and with it, cultural products need to speak about this kind of progress, and Huawei's advertising claims that its own progress is centered on Western-style modernization. In the design of advertising scenes, scenes with Western characteristics are advanced, while scenes with Chinese characteristics lag behind. Therefore, those that need to be transformed or abandoned are those to be transformed in Huawei's progressive narrative.

1. Zhou Ning. China in the World: A Study on the Image of China Outside the Territory [M]. Nanjing: Nanjing University Press, 2007.9.51. 


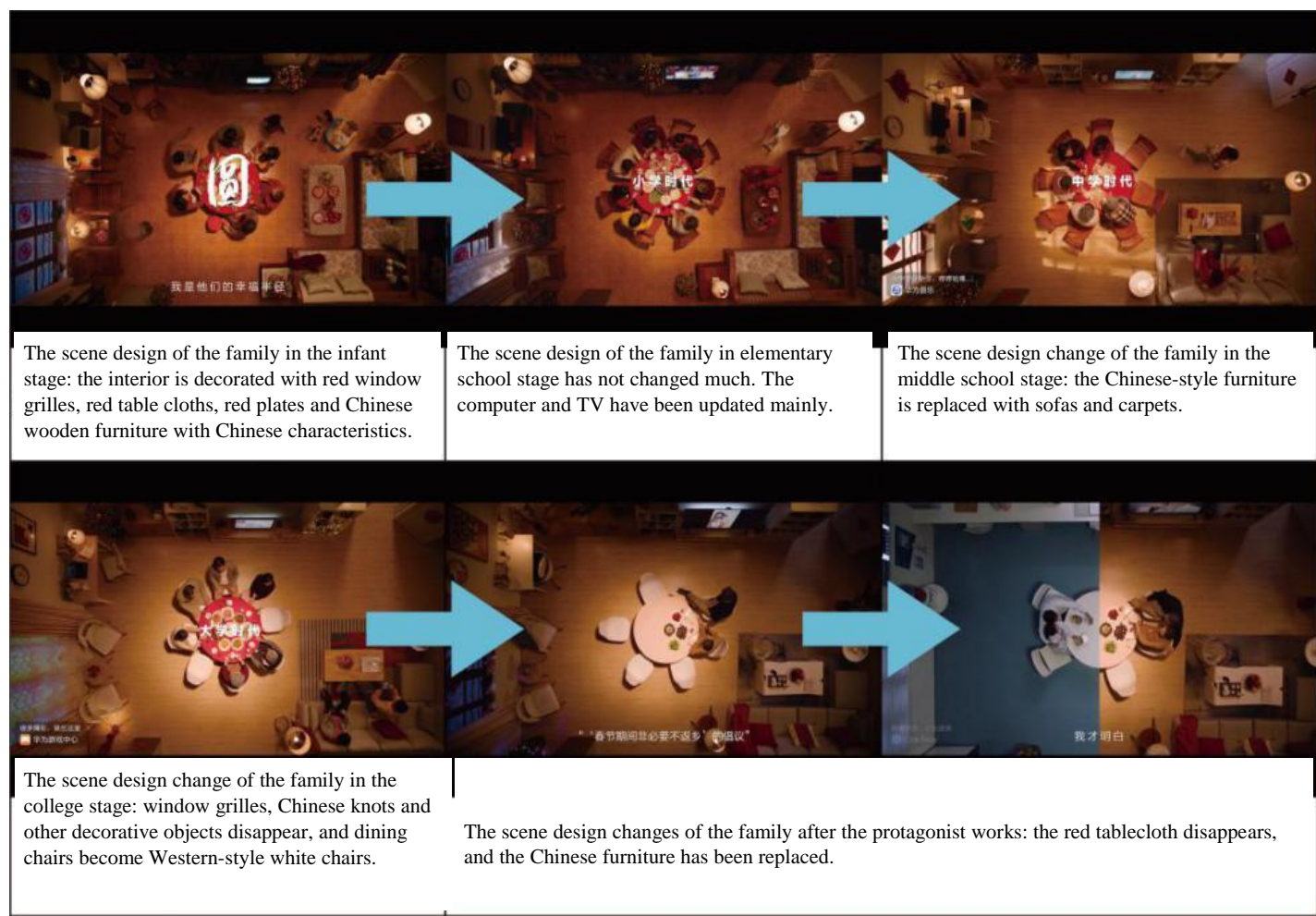

Figure 1 Huawei advertisement "Circle" in 2021.

Huawei's 2021 New Year's advertisement "Circle" centers on a round table for a family to eat, and records that over time, Huawei products have brought convenience to users in life.("Figure 1") This advertisement is dedicated to promoting functions such as Huawei Cloud Music, Huawei Game Center, Huawei Wallet, Huawei MyCloud and Link Now ${ }^{2}$. The advertisement presents the five life periods of the protagonist from infant stage, elementary school, middle school, college to entering the workplace. The way Huawei presents timed transition is the indoor scene layout: Chinese elements (red window grille, red table cloth and Chinese knot) are gradually reduced, and Westernstyle furniture slowly appears on the stage until Chinese-style furniture is completely replaced with Western-style furniture, using the disappearance of Chinese elements and the Westernization of furniture to reflect the gradual modernization of the family in the advertisement.

2. Huawei online collaborative office software

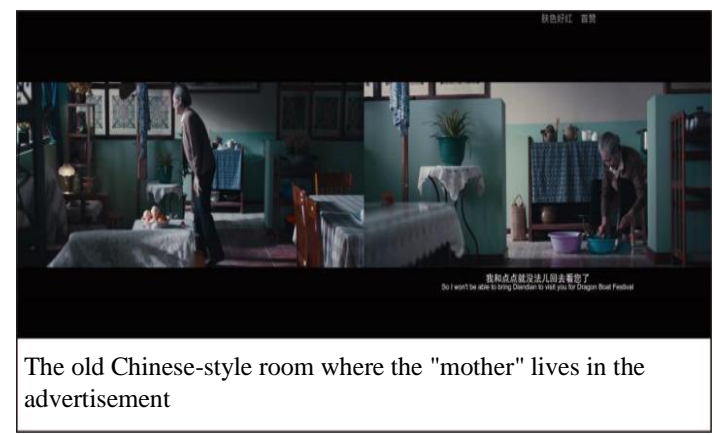

Figure 2 Huawei advertisement "Water Meter" in 2020.

Huawei's advertisement "Water Meter" on the Dragon Boat Festival in 2020 tells such a story: A mother missed her children, but after knowing that her children were too busy at work during the Dragon Boat Festival and couldn't go home for the holidays, she kept catching water so that the smart water meter sent abnormal water usage data to her children to arouse their vigilance, and afterwards, the children returned to their mother's house for "reunion" on Dragon Boat Festival. ("Figure 2") In the advertisement, the contrast between the two different scenes is very obvious: One is the modern office space where the children live, and the other is the mother's home - the old Chinese-style building. As the children chase their ideal life, this 
old building has been kept away, so it is an object that needs to be transformed. Thanks to modern equipment - the smart water meter, children return to their childhood home. The children live in an environment that is not in urgent need of modern equipment - Huawei products, because it is already Western-style and advanced. The outdated Chinese-style old building needs modern smart equipment, which is more convenient on the one hand, and is used to promote family reunion on the other hand. In this advertisement, the scenes with
Chinese characteristics appeared in a backward state, so that they were "abandoned", and then awakened the emotions of the characters in the advertisement in a warm way, and reached an emotional resonance with the audience. According to the plot needs of this advertisement, Huawei compares the Western advanced scenes and China's lagging scenes to isolate them or transform these backward Chinese scenes, considering these features to be outdated and therefore need to be transformed.

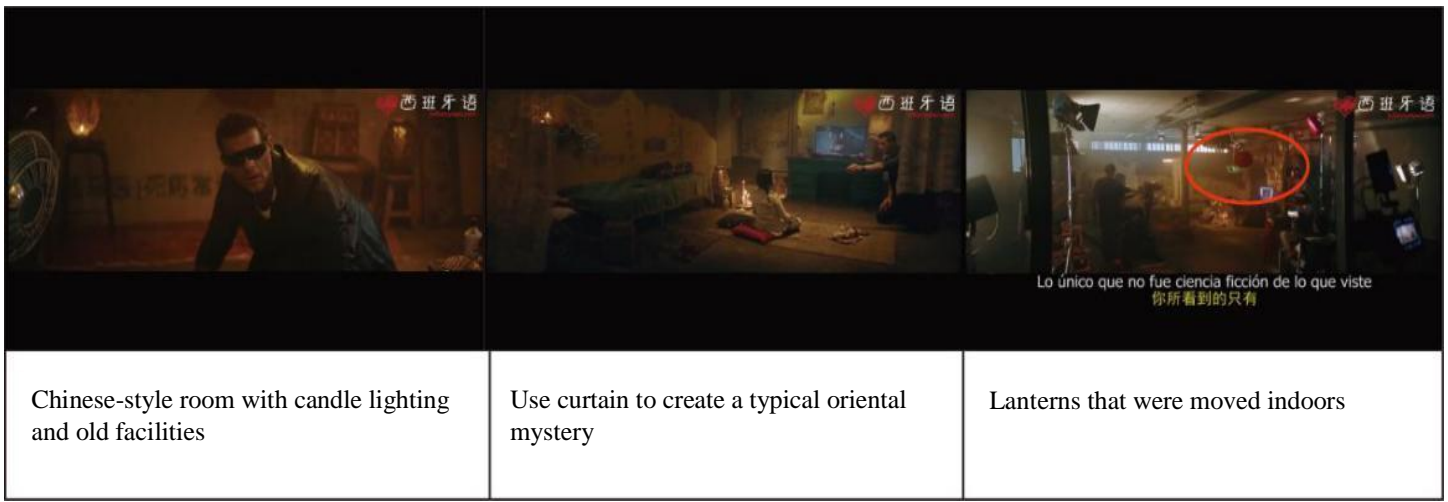

Figure 3 Huawei's advertisement "Looking for 'Hope'" in 2017.

"Looking for 'Hope'" is a Spanish advertisement that Huawei launched in Peru in 2017. ("Figure 3") It tells the story of Emmett, a soldier in the future rescue operation of the West, passing through the "gateway of time" in an abandoned pipe to the home of a little Chinese girl (Hope). And this little Chinese girl is the mysterious one to be rescued in the East. In the advertisement, the arrangement of "home", the environment where the Chinese little girl is located, presents a mysterious treatment. For example, through the existence of electrical equipment such as television and electric lamp, it can be judged that this is not an era without electricity, but candles can be seen everywhere in the room, and candles are often associated with ancient and mysterious occasions. The Chinese lanterns that are supposed to be outdoors are moved indoors for lighting purposes. The misuse of the function of lanterns is also shown in Zhang Yimou's movie "Raise the Red Lantern". A series of ritual customs such as lighting on, lighting off, lighting incandescent light, and sealing light are designed to cater to the mysterious imagination of the West about China. "Raise the Red Lantern" deliberately rendered a very strange and mysterious ritual to Western audiences: The hanging of the lantern means that the male protagonist will enter the boudoir of a certain wife, which has a symbolic meaning of sex and politics. This kind of fictitious "pseudo folklore" makes Western audiences more curious about the East, Eastern culture, and Eastern people. Whether intentionally or not, the description in the film satisfies the Western psychology of curiosity. ${ }^{3}$ The Chinese proverbs written on the curtains and walls in the little girl's room in the advertisement are also intended to create a typical oriental sense of mystery and haziness. The advertisements show the backward Chinese scenes in line with Western imagination, not only to set off the advanced nature of Huawei products, but also to cater to the Western market with China in line with Western imagination, giving Western consumers a sense of familiarity rather than a strong sense of cross-cultural strangeness. However, this way of setting off the advanced nature of its products with backward Chinese scenes is not conducive to the foothold of the Huawei brand in overseas markets in the long run. As a Chinese company, Huawei can better win consumers' trust in products by presenting a strong and modern image of China.

3. Yu Jiali. The Criticism and Countermeasures of "Self-Odentalism" in Chinese Films in Global Age $[\mathrm{J}]$. Contemporary Cinema, 2007(06):148-150. 


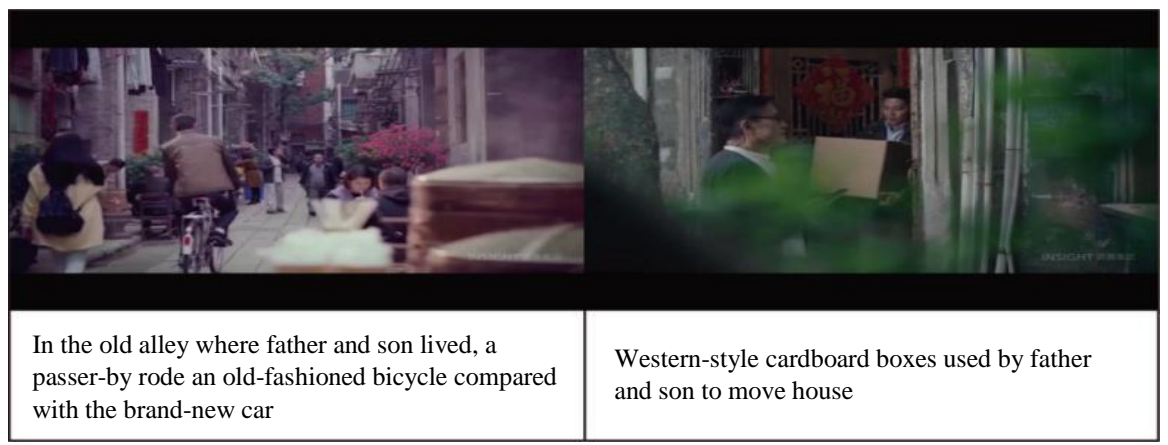

Figure 4 Huawei Cloud Gallery advertisement in 2016.

Huawei launched an advertisement for the cloud gallery function in 2016 - "Whether there is a moment when you regretted deleting the memories with him". This advertisement tells the story of a father and son about to move away from the old alley where they lived for many years. The old father reluctantly shoots the characters and scenes in the old alley. ("Figure 4") Here, the advertisement's treatment of the public space with Chinese characteristics is to photograph the dilapidated street scene and then isolate it. The father and son are about to move away from the old alley, and their living environment has improved. The difference from old to new is reflected in several details. For example, there is a contrast between the old-fashioned bicycles used by passers-by in the alleys and the brand-new car of his son. The son moves house with cardboard boxes without any trademarks, which are often used when moving in the West or Japan. Here, Huawei has westernized the details of the moving of Chinese people, which is deliberately distinguished from the moving method of the Chinese public. This advertisement uses these details to consciously distinguish the difference between the product users - father and son and the residents living in the old alley, in order to enhance the image of the product.

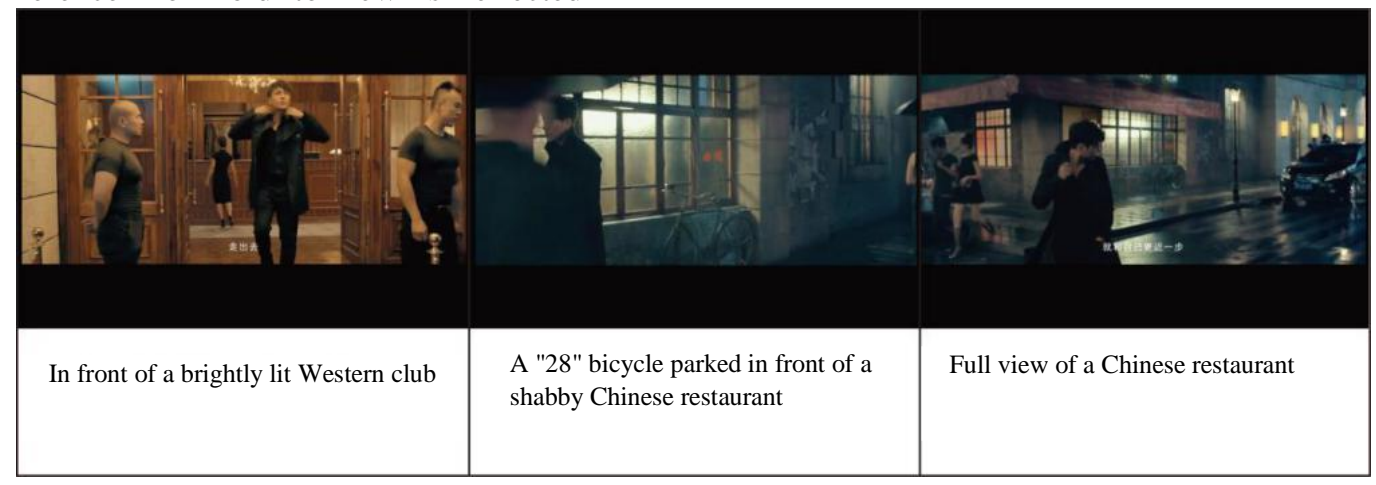

Figure 5 Huawei Honor 7 advertisement in 2015.

In 2015, Chinese film star Chen Kun starred in the protagonist of Huawei Honor 7 mobile phone advertisement. The advertisement used a one take approach to deal with the process of Chen Kun walking from the club to the outdoors, accompanied by a narration to state the concept of life, and finally led to the slogan — "GO! Be brave, glorify yourself". At the beginning of the advertisement, Chen Kun appeared in a very westernized indoor club. The expressions of people in this space are very relaxed and enjoyable, because there are good wines, bands, and ablaze with lights. The camera followed Chen Kun to the outdoor street. With the appearance of dilapidated walls, old Chinese-style windows appeared immediately, with words such as "snacks", "noodles" and "restaurants" pasted on the glass. This was a Chinese-style restaurant that didn't even have a decent signboard. There was a "28" bicycle (referring to a kind of bicycle with a wheel diameter of 28 inches) popular in the 1960s and 1970 s at the door. People coming out of the small Chinese-style restaurant were all in a hurry, which was in sharp contrast to the people enjoying themselves in the Western club. "Club" and "Chinese-style restaurant" are the manifestations of Western and Chinese styles respectively. ("Figure 5") The advertisement has a special time lag 
treatment for the Chinese restaurant so as to set off the advanced nature of Huawei's products. The famous American scholar Thomas Sowell said in the ethnic Chinese chapter of his book "Ethnic America: A History" that Chinese-style restaurants are one of Westerners' impressions of Chinese people, which originated from the first generation of immigrants from China to America. Because they couldn't integrate into American society, the ethnic Chinese could only make a living by opening restaurants in Chinatown. The advertisement undoubtedly caters to the Western imagination of China. This Huawei Honor advertisement uses selforientation to set off the modernization of the Honor mobile phone, which represents the achievement of Western technology.

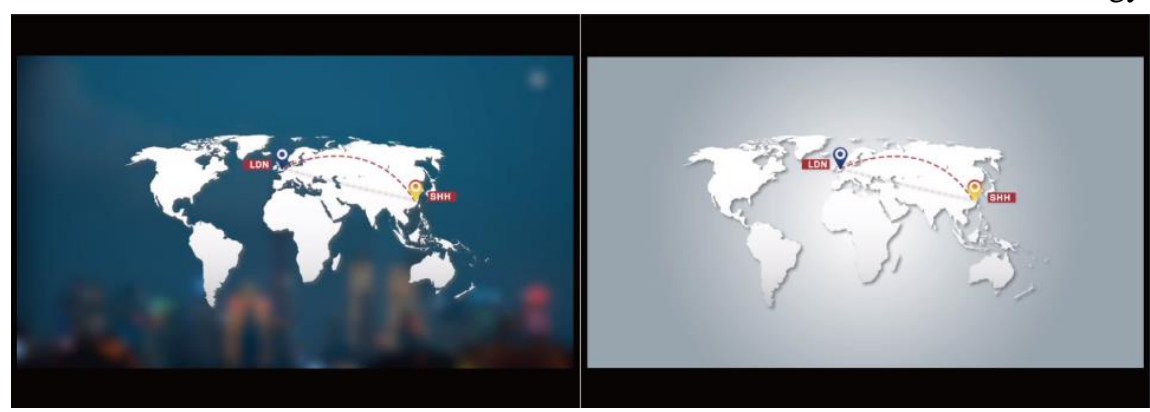

Figure 6 The world map in Huawei's advertisement "Fate, Too Wonderful for Words" in 2018.

In 2018, Huawei's advertising "Fate, Too Wonderful for Words" was a series of advertisements promoting mobile phone shell, which was divided into four episodes. The advertisement told the love story of a long-distance couple. The male protagonist came to Shanghai from London on a business trip and met the female protagonist working in Shanghai. The two developed the affection for each other and began a long-distance relationship. At the beginning of each episode, a map of the world would be marked to indicate the city where the couple were in the advertisement. It is worth noting that this is a series of advertisements placed in China, and Huawei uses a world map commonly used in Western countries with London as the center, which is different from the world map with China as the center. Different maps of the world carry a country's self-centered will. In the eleventh year of Wanli (the year of 1583), Matteo Ricci hung out the map of the world he brought from the West for the first time in Zhaoqing, Guangdong... The location and size of China on the map aroused dissatisfaction among some officials. Wang Pan saw the map engraved by Matteo Ricci "putting China at the extreme east corner of the map, and he was angry". ${ }^{4}$ Matteo Ricci brought the world map with Europe in the center to China for the first time, which changed the traditional Chinese geographical perception of the "orbicular sky and rectangular earth", but some Chinese officials at that time were extremely dissatisfied with the map drawing

4. Zhao Yingli. The Prime Meridian of Matteo Ricci's World Map [J]. Map, 2005(04):43-47. method of China being on the edge of the world. Therefore, in order to cater to the Chinese people's concept of "The Celestial Empire", Matteo Ricci moved China to the center of the world map to facilitate the development of his missionary work. This is also the predecessor of the world map used in China today. Matteo Ricci's move to change the map reflects the Chinese people's confidence in their national power and culture during the Ming Dynasty. The China in Huawei's advertisement is on the edge of the east of the world, and Huawei has adopted self-Orientalism in terms of geographic location.

Huawei advertising uses time lag processing of scenes with Chinese characteristics, and borrows advanced Western scenes to set off the superiority of its products, such as placing users of Huawei products in modern Western-style scenes, and using backward Chinese-style scenes as a foil to strengthen the advanced nature of Western-style scenes, so that viewers of advertisements will have the feeling of envy. This method of distinction is accomplished through the modernization of Western-style scenes, forming a dual structure of opposition between China and the West, the old and the new, and the past and the modern on the whole.

\section{THE UNREFORMED CHINESE SCENE IN THE NARRATIVE OF CHINESE PROGRESS}

The 2018 Huawei advertisement "Fate, Too Wonderful for Words" and the 2016 Apple advertisement "iPhone 7 Plus — The City" were 
both shot in Shanghai, China, and the narrative content of the two advertisements is very similar. ("Figure 7") Both advertisements filmed couples playing in the city, but the Shanghai style and features they showed were completely different. The Shanghai streetscape chosen by Apple is very old. The streets, lined with shabby billboards and cluttered bicycles, are crowded with people. People are mostly expressionless and the atmosphere is dull. In this advertisement shot on the riverside of Shanghai, the weather is very dim, there is no light when night fell, Shanghai's buildings account for about one-third of the scene, and the lens fail to highlight the prosperous high-rise buildings in Shanghai. However, the streets of Shanghai in Huawei's advertisement are very tidy, with bright sunshine during the day and bright lights at night, reflecting the modernization of Shanghai and the vigorousness of Shanghai people everywhere. In the same shot of Shanghai riverside, high-rise buildings occupy two thirds of the scene, which makes people feel the prosperity and advancement of Chinese cities.

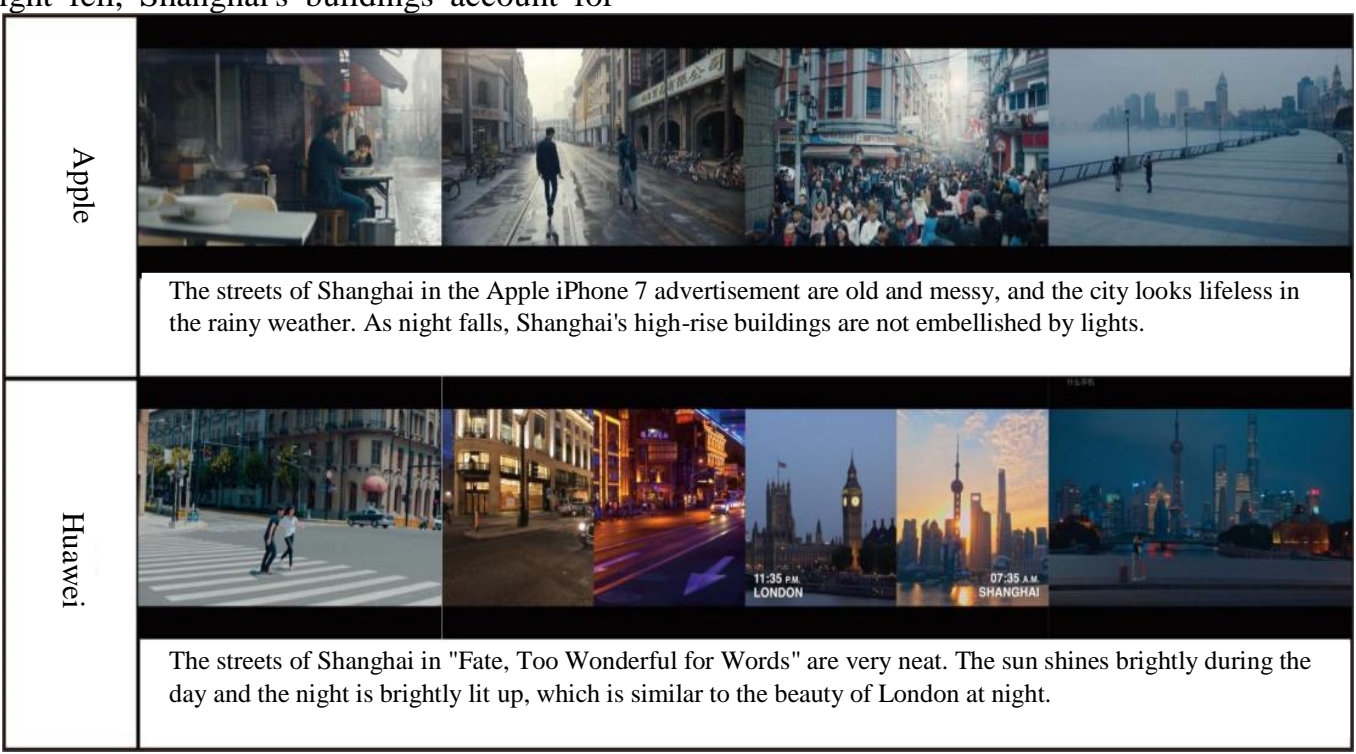

Figure 72018 Huawei advertisement "Fate, Too Wonderful for Words" and the 2016 Apple advertisement "iPhone 7 Plus - The City".

"It doesn't matter whether Chinese civilization has actually stagnated. What is important is that the discovery of a foreign image of a 'stagnant empire' can confirm a belief that embodies the liberal spirit of enlightenment and the progress represented by Western civilization". 5 The street scenes shot in Apple's advertisement create an illusion that is out of touch with modern Shanghai. It is lagging in time and doesn't show the advanced nature of modern Shanghai. As an American brand, Apple still enters the Chinese market with an arrogant attitude, ignoring the fact that China is progressing, and continuing to create the illusion of China's backwardness to reflect the advancement of Apple products is inopportune. Huawei's display of a modern Chinese city image in the Chinese market can enhance the national cultural self-confidence of the Chinese people and their trust in the Huawei

5. Zhou Ning. China in the World: A Study on the Image of China Outside the Territory [M]. Nanjing: Nanjing University Press, 2007.9.51. brand. In the international market, this can change the overseas impression of China's backwardness to some extent, thereby enabling foreigners to trust Chinese brands and promoting brand sales.

\section{CONCLUSION}

The First World holds the absolute power of cultural media and knowledge production, regards its own ideology as an "eternal" and "detached" world value, and encodes its own prejudices and imagination in the entire cultural machine to compulsively instill into the Third World. The culture of the Third World is in a marginal and repressed position. ${ }^{6}$ In this context, how Chinese brands can find a way to survive should become an urgent issue, instead of blindly borrowing the Western time logic of advanced West and backward China to promote product sales. Through the

6. Zhao Xifang. Postcolonial Theory $[\mathrm{M}]$. Peking University Press, 2009. 
interpretation of the scene design in Huawei's advertising, this article hopes to inspire China's mobile terminal corporate advertisements in terms of scene layout, and hopes that corporate advertisements can be wary of the illusion of China's backwardness that the West uses to establish its own advanced nature. Such similar corporate advertisements should show the real scenes of modern China, establish a good brand image through scene design, and gain the trust of consumers.

\section{AUTHORS' CONTRIBUTIONS}

This paper is independently completed by Yaling Zhang.

\section{REFERENCES}

[1] (America) Edward W. Said, translated by Wang Yugen. Orientalism [M]. Beijing: SDX Joint Publishing Company, 2019.9. (in Chinese)

[2] Zhou Ning. China in the World: A Study on the Image of China Outside the Territory [M]. Nanjing: Nanjing University Press, 2007.9. (in Chinese)

[3] (French) Bourdieu, translated by Liu Hui. la distinction: critique sociale du judgment (Volumes 1 and 2) [M]. Beijing: The Commercial Press, 2015. (in Chinese)

[4] (United States) Mike Davis, translated by Pan Chunlin. Planet of Slums [M]. Beijing: New Star Press, 2009.11. (in Chinese)

[5] $\mathrm{Xu}$ Yaning. Viewing the time logic of American films shaping the "East" from a post-colonial perspective [J]. Foreign Languages Research, 2015(02):13-16. (in Chinese)

[6] Zhao Xifang. Postcolonial Theory [M]. Peking University Press, 2009. (in Chinese)

[7] Zhou Xibing. Internationalization of Huawei [M]. CITIC Publishing House, 2020. (in Chinese)

[8] Shi Yujie. An Orientalist Interpretation of the Movie "Raise the Red Lantern" [J]. Journal of Language and Literature Studies, 2016(03):79-80+84. (in Chinese)
[9] Zhao Yingli. The Prime Meridian of Matteo Ricci's World Map [J]. Map, 2005(04):43-47. (in Chinese)

[10] Wenxian Zhang, Ilan Alon, Christoph Lattemann. Huawei Goes Global [M]. Palgrave Macmillan, Cham:0.

[11] Baolin Huang. Research on Brand Marketing Strategy of Huawei Mobile Phone in the New Era [J]. International Journal of Intelligent Information and Management Science, 2019,8(6). 